\title{
The Role of Harvest Index in Improving Crop Productivity: A Review
}

\author{
Gemechu Asefa \\ Ethiopian Institute of Agricultural Research, Jimma Agricultural Research Center, Jimma, Ethiopia
}

\begin{abstract}
Harvest index (HI) is a measure of success in partitioning assimilated photosynthate. An improvement of crop harvest index means an increase in the economic portion of the crops in certain level. HI is a novel trait which contributed significant role in improvement of crop productivity which could solve the problem of food supplies for the rapidly increasing population. The objective of this paper was to review the role and progress of $\mathrm{HI}$ in improving crop productivity. Although crop $\mathrm{HI}$ influenced by both environmental and genetic factors, the progress improvement of $\mathrm{HI}$ and yield through crop management technique and breeding method strategy is an anticipative. In addition, the knowledge of genetic mode of expression of HI provides information for breeder to determine next breeding method.
\end{abstract}

Keywords: Additive, Environmental, Genetic, Harvest index, non additive, productivity

DOI: $10.7176 / \mathrm{JNSR} / 9-6-04$

Publication date:March $31^{\text {st }} 2019$

\section{Introduction}

The production of yield in cropping systems is a consequence of many biological processes resulting in biomass and/or seed production. Economic yield and biological yield (biomass) are terms used to describe dry matter partitioning in plants. Harvest index(HI) is the ratio of grain yield to total biomass (Donald and Hamblin 1976; Hay, 1995 and Sinclair, 1998) is a trait that is the cumulative result of allocation of acquired resources and used in efforts to improve yields in seed producing crops (Reynolds and Langridge, 2016). HI is one of the factor that contributing in improvement of any crop to a certain extent (Reddy et al., 2003). It describes plant capacity to allocate biomass (assimilates) into the formed reproductive Parts and important trait in plant breeding (Wnuk et al., 2014). Also, the harvest index can be defined as been the physiological efficiency and ability of a crop for converting the total dry matter into economic yield (Sharifi et al., 2009).

In several crops, such as wheat or other cereals, the considerable progress in breeding for higher yields is achieved mainly through man-made selection forces for the harvest index (Gutam, 2011; Mazid et al., 2013). According to Yang and Zhang (2010) the proper crop management holds great promise to enhance harvest index, and consequently, achieve the dual goal of increasing grain production and saving water.

Some researchers indicate that the dramatic increase in the grain yield of major world cereal crops is due mainly to increases in harvest index and to a lesser extent the biological yield. In cereals it is generally accepted that the major contribution of plant breeding to improved yields has been through increased HI (Wilson, 1987). In maize, for example, harvest index changed from $24 \%$ in 1950 to $43 \%$ in 1970, increasing yield from 3 tons/ha to 8 tons/ha (Acquaah, 2009).

Despite this, currently, food production for a rapidly growing population and climate change is the major challenge. Improving yield of grain crops is needed to ensure food supply for the rapidly increasing population. However, without improving harvest index, increase in yield could not be achieved. In view of this, harvest index play significant role in improving crop productivity, and the objective of this paper was to review on the role and progress of harvest index in crop productivity.

\section{Discussion}

Importance of harvest index (HI)

Yield, in the eyes of breeders, is considered to have two main components: biomass, the ability to produce and maintain an adequate quantity of vegetative material, and partition, the capacity to divert biomass to the desired harvestable product (seeds, fruits, or tubers etc.). Therefore, the partitioning of assimilate is very important in obtaining maximum yielding ability. Partition, in general, takes the form of enhancement of yield of desired parts of the plant product at the expense of unwanted plant parts (referred to as increasing the harvest index) (Jack et al., 2014).

Yield of a crop is the function of biomass $\mathrm{x}$ harvest Index. Different authors indicated, yield improvement associated with increasing harvest Index (Sharma-Natu and Ghildiyal, 2005). Low crop harvest index is the major cause of less crop yield and vice versa. Ambrose and Hedley (1984) reported that $95 \%$ of the plants in a high yielding pea crop had harvest index (HI) values of 40 to $70 \%$. The HI may increase or decrease if seed yield changes more, or less, rapidly than total dry matter (TDM).

Harvest index could be used as selection criteria for breeder to improve yielding ability of a given crop. It is 
useful in describing yield differences between lines. It is an appropriate trait to target for increasing yield potentials for crop breeding activities (Sadras and Richards, 2014). The highest seed yields are often associated with high HIs which then become an important selection criterion in plant breeding (Pilbeam, 1996). A more comprehensive understanding of harvest index and the basis upon which variations in harvest index are achieved among different genotypes would be of considerable advantage to food production systems. Genotypes expressed higher HI can be considered as ideal materials for selection in order to improve yield productivity, and therefore, harvest index could be included as the objective of plant breeder. Different authors reported high yielding varieties generally gave higher HI than lower yielding varieties among sweet potato landraces (Kays, 1985; Nwankwo et al., 2018).

\section{Factors Cause variation of harvest index (HI) \\ Between crop species}

Harvest index which measure the degree to which crop partitions photo assimilate into grain varied among crop species. This may due to the difference in growth habit, difference growth stage, the ripening period or fruit setting varied among crops. Harvest index (HI) of root and tuber crops greater than $\mathrm{HI}$ of grain crops and the HI of watermelon (Citrullus vulgaris) is $\geq 0.9$ (Ismail, 1993). In cereals, HI values between 0.3 and 0.6 dominate (Hay, 1995). Harvest index also varied among different cultivar or lines of similar crop species. Abdalla et al. (2015) reported variations in harvest index among lines of fababean irrespective of environments, line C.86 had higher harvest index $(32.4,43.4$ and 35.8) in the three seasons, respectively. However, Triple White line had the lowest mean harvest index $(21.2 \%, 37.3 \%$ and $25.7 \%)$ in the three seasons respectively.

Most cereal crop cultivars are determinate, flowering within a very small skylight of time and then entering a grain-filling period such that vegetative and reproductive growth is separated in time. Determinate crops generally have higher harvest indices as most crop resources are diverted to grain production once flowering has commenced. Harvest index more variable in indeterminate than determinate crops (Unkovich et al., 2010).

\section{Environmental variation}

Climate change influenced crop growth parameter leaf a Leaf area index (LAI), aboveground dry matter (ADM), and harvest index (HI). Change of climatic parameters such as increasing of temperature and precipitation decreased the grain production which resulted in lower values of HI (Banu et al., 2017).

Effect of temperature on harvest index (HI): For most plants reproductive development is sensitive to a wide range of environmental impacts, with many grain crops having a preferred temperature range for flower and seed development. Large variations in temperature outside of this range may cause problems with flower or seed growth. Temperature stresses on reproductive performance of crops also affect HI. Seed or flower development is constrained due to specific effects on reproductive apparatus; harvest index is likely to be significantly reduced, especially for determinate crops. The simplest example of a temperature extreme is frost, with freezing injury causing flower or seed abortion (Unkovich et al., 2010).

Heat and drought: Heat and drought have multiple, negative impacts on crop yields, including reducing leaf photosynthesis and enhancing leaf senescence rates. More critically for yield determination, however, are the reported effects of decreasing grain number when heat stress occurs before or around anthesis and reduced grain weight when it occurs during grain filling (Dolferus et al., 2011; Ugarte et al., 2007). While drought represents a process that develops and intensifies slowly, heat stress can occur very abruptly and even short episodes of high temperature can cause a severe decline in grain yields. Short occurrence of heat stress can reduce crop yield considerably causing low resource use efficiency (Siebert et al., 2014). These results are an important indicator that factors contributed to crop yield losses are directly cause lower values of harvest index.

Crop growth season: Highest harvest index was recorded under favourable environmental condition than unfavourable condition over three growing season of fababean (Abdalla et al., 2015). Similarly, Harvest index registered higher values under more favourable soil and climatic conditions than under less favourable conditions in different maize growing areas (Ion et al., 2015).

Mohamad et al. (1994) reported harvest index was higher in main season (40.2\%) than off-season (35.2\%) among rice varieties. The harvest index among 20 released rice varieties was ranged from 0.29-0.42 and 0.31-0.51 in offseason and main season, respectively.

Harvest index tended to correlate negatively to plant height when the climatic conditions were less favourable for growing maize and tended to correlate positively up to a certain level when the climatic conditions were more favourable, especially when these were associated with favourable soil conditions (Ion et al., 2015). 
Table 1: Harvest index of different crop species

\begin{tabular}{cccc}
\hline Crop species & Yield(kg/ha) & HI & References \\
\hline 11 variety of haricot bean & $678.2-2709.3$ & $0.28-5.0$ & Tadesse et al.,2014 \\
3 variety of haricot bean & $2246-2376$ & $0.5-0.55$ & Girma et al.,2014 \\
3 varieties of common bean & $13247-14932$ & $0.28-0.35$ & Melaku .,2012 \\
6 faba bean line & $2546-5353$ & $0.21-0.43$ & Abdalla et al., 2015 \\
6 potato variety & $7530-14240$ & $0.7-0.8$ & Mazurczyk et al.,2009 \\
10 varieties of sweet potato & $8090-17390$ & $0.35-0.53$ & Nwankwo, et al., 2018 \\
maize & - & $0.2-0.56$ & Ion et al.,2015 \\
10 winter wheat varieties & $5800-7760$ & $0.48-0.56$ & White and Wilson,2006 \\
26 spring wheat genotypes & $6000-7500$ & $0.45-0.51$ & Foulkes et al.,2015 \\
20 released varieties of rice & $556-996 \mathrm{gm} / 20 \mathrm{plants}$ & $0.31-0.51$ & Mohamad et al.,1994 \\
\hline
\end{tabular}

\section{Crop management}

Different level of crop management influence harvest index ultimately improves crop productivity. Bekele et al. (2016) reported highest harvest index (35.3\%) recorded from intercropped maize and soybean than sole cropped maize (31.7\%). Getachew(2007) also reported that higher harvest index was from intercropped maize with potato than sole cropped maize. In contrary to this, Gutu et al.(2015) reported sole maize cropping system gave higher harvest index (0.39) than intercropped maize and soybean $(0.37)$.

Plant population: Different authors reported highest HIs obtained at high plant population densities. According to Ion et al. (2015) the highest average values of the harvest index were registered at plant density of 70.000 plants ha-1 in maize. Kerby et al. (1990) pointed out that high plant density in cotton resulted more dry matter leaves and stems relative to fruit and thereafter low harvest index (HI). The higher number of HI (38.11\%) was obtained from $25 \%(83,333$ plants $/$ ha) soybean population than $50 \%$ and $75 \%$ soy bean populations (Gutu et al., 2015).

Nutrients: Application of potassium (K) at the highest rate $\left(90 \mathrm{~kg} \mathrm{ha}^{-1}\right)$ increased Harvest index $(0.39)$ due higher $\mathrm{K}$ level was attributed to the more dry matter partitioning into the reproductive parts (ears) of maize (Amanullah et al.,2015). Ayaz (2001) reported nitrogen increased total dry matter (TDM) yield and seed yield, but the proportion of TDM was higher than seed following application of $\mathrm{N}$ to legumes. The HI of the legumes is reduced due to a comparatively high increase in TDM production.

According to Reddy et al. (2003) any approach which promotes remobilization of photosynthates from vegetative to reproductive organs influences $\mathrm{HI}$ and thus productivity. Soil application of boron $(2 \mathrm{~kg} / \mathrm{ha})$ at ray floret stage increased the $\mathrm{HI}$ to an extent of $29 \%$ and the seed yield by $53 \%$. Boron is known to play an important role in translocation of sugars.

\section{Mode of Inheritance of Harvest Index}

The genetic control of harvest index plays an important role in improving crop productivity. The inheritance mode of harvest index was mainly by additive gene action, as was heading date, plant height, and 100 seed weight. Harvest index showed higher narrow sense heritability than plant weight and grain yield. Heritability of harvest index was highest in stress environments (Rosielle, 1975).

Monpara and Gaikwad (2014) stated estimates of heritability for HI were low to high (36.29-91.01\%), where as those of genotypic coefficient of variation (GCV: 16.06-92.38\%) and genetic advance (15.55-84.58\%) were moderate to high in populations studied. However, moderate to high magnitude of heritability coupled with high genetic advance and high GCV in four out of six crosses indicated that the gene action governing the expression of HI was largely due to additive in nature and improvement in this trait is possible through selection.

Ur-Rehman et al. (2005) reported for harvest indexes both additive and non additive gene action was significant in both F1 and F2 generations of diallel analysis in mung bean. The relative contribution of additive gene effect was more preponderant than non-additive in F1 while in F2 non additive gene action (dominance) was higher than additive genetic effect for harvest index in mung bean. Pinto Júnior et al.(2018) reported highly significant mean square of both GCA and SCA for HI in their study of diallel analysis griffing method II in common bean. They found average HI of F2, F3 and F4 ranged from 0.28 to 0.42 and 0.20 to 0.38 for parents and hybrids, respectively.

The mean square due to GCA and SCA was significant in both F1 and F2 progenies of a ten-parent diallel cross (excluding reciprocals) of hexaploid wheat for harvest index and yield. However, the general combining ability (gca) component of variance was predominant than specific combining ability (sca) indicating the predominance of additive gene effects for these traits in wheat (Joshi et al., 2004). In line to this, Chand et al. (1996) found that additive gene action was important for the expression harvest index in wheat.

\section{Conclusion}

Harvest index (HI) is the proportion of percentage of grain yield to total biomass. It is a novel trait which directly 
associated with yield, and the capacity of a crop for diverting the total dry matter into economic yield. The harvest index of different grain crops couldn't achieved to the range of upper limit value. Therefore, the objective of this paper was to review the role and progress of HI in improving crop productivity. The HI is variable to genetic factors and environmental factors. The genetic mode of expression of HI also substantially varies among crops which assist breeder to determine breeding strategy for enhancement of crop productivity. Improvement of this trait offer higher grain yield among some crop species. Hence, greater emphasis could be placed on breeding program for high harvest indexes for crop species to identify conditions and genotypes associated with a stable, higher harvest index and higher yield, simultaneously.

\section{Reference}

Abdalla, A.A, El Naim, A.M, Ahmed, M.F and Taha M.B (2015). Biological Yield and Harvest Index of Faba Bean (Viciafaba L.) as Affected by Different Agro-ecological Environments. World Journal of Agricultural Research, 3: 78-82.

Acquaah, G (2009). Principles of plant genetics and breeding. John Wiley \& Sons.

Amanullah, A, Iqbal A and Iqbal M (2015). Impact of potassium rates and their application time on dry matter partitioning, biomass and harvest index of maize (Zea mays) with and without cattle dung application. Emirates Journal of Food and Agriculture. 27: 447-453

Ambrose M.L and Hedley C.L (1984). A population study to aid the selection of improved dried pea (Pisum sativum) crop plants. Annals of Botany 53:655-662.

Ayaz S (2001). Variability of harvest index in four grain legume species. Doctoral dissertation at Lincoln University.229P.

Banu S, Atiku Rahman A and Adham A (2017). Assessment of the effect of climate change on vegetative growth of major crops in Bangladesh using DSSAT. Fundam Appl Agric, 2: 317-325

Bekele W., Belete K. and Tana, T ( 2016). Effect of soybean varieties and nitrogen fertilizer rates on yield, yield components and productivity of associated crops under maize/soybean intercropping at Mechara, Eastern Ethiopia. Agriculture, Forestry and Fisheries, 5 : 1-7.

Chand K, Dawa T and Chaudhary H.K (1996). Combining ability and Gene effects for yield and other quantitative traits in inter-varietal crosses in bread wheat. J. Hill Res, 9: 303-308.

Dolferus R., Ji X and Richards, R.A ( 2011). Abiotic stress and control of grain number in cereals. Plant science, 181: 331-341.

Donald CM, Hamblin J (1976). The biological yield and harvest index of cereals as agronomic and plant breeding criteria. Adv Agron, 28: 361-405.

Foulkes J., Rivera C., Trujillo E., Sylvester-Bradley R and Reynolds M (2015). Achieving a step-change in harvest index in high biomass wheat cultivars. Proceedings of the International TRIGO (Wheat) Yield Potential. Work shop Sonora, Mexico 24-26th March, pp 31-36.

Getachew Selamawit.(2007). Effect of Plant Population and Nitrogen Fertilizer on Growth and Yield of Intercropped Potato (Solanumtuberosum L.) and Maize (Zea mays L.) at Haramaya, Eastern Ethiopia. M.Sc. Thesis, Haramaya University.

Girma A, Demelash A and Ayele T (2014). The Response of Haricot bean varieties to different rates of Phosphorus at Arbaminch, southern Ethiopia. Journal of Agricultural and Biological Science, 9:344-350.

Gutam S. (2011). Dry matter partitioning, grain filling and grain yield in wheat genotype. Communications in Biometry and Crop Science, 6: 48-63.

Gutu T, Tana T, Geleta N (2015). Effect of Varieties and Population of Intercropped Soybean with Maize on Yield and Yield components at Haro Sabu, Western Ethiopia. Science, Technology and Arts Research Journal, 4: 31-39.

Hay RK (1995). Harvest index: a review of its use in plant breeding and crop physiology. Annu Appl Biol, 126 : 197-216.

Ion, V., Dicu, G., Dumbravă, M., Temocico, G., Alecu, I.N., Băşa, A.G. and State, D. ( 2015). Harvest index at maize in different growing conditions. Romanian Biotechnological Letters, 20 : 10951-10960

Ismail (1993). A Critical analysis of harvest index. Qatar Univ. Sci. J., 13: 253 - 263.

Jack B., Peter D.S. Caligari, Hugo A. Campos (2014). Second Edition of Introduction to Plant Breeding . University of Idaho, USA and Monsanto, p.295.

Joshi S.K., Sharma S.N., Singhania D.L. and Sain, R.S ( 2004). Combining ability in the F1 and F2 generations of diallel cross in hexaploid wheat (Triticum aestivum L. em. Thell). Hereditas, 141 : 115-121.

Kays SJ (1985). The physiology of yield in sweet potato. In . J.C. Bouwkamp, (eds). Sweet potato products: natural resources for the tropics. $C R C, \mathrm{P} .77-132$.

Kerby T. A., Cassman K. G. and Keeley, M (1990). Genotypes and plant densities for narrow row cotton system II. Leaf area and dry matter partitioning. Crop.Sci., $30: 649-633$.

Mazid M.S., Rafii M.Y., Hanafi M.M., Rahim H.A., Latif M.A (2013). Genetic variation, heritability, divergence 
and biomass accumulation of rice genotypes resistant tobacterial blight revealed by quantitative traits and ISSR markers. Physiologia Plantarum 149: 432-447.

Mazurczyk W., Wierzbicka A. and Trawczynski, C (2009). Harvest index of potato crop grown under different nitrogen and water supply. Acta Scientiarum Polonorum. Agricultura, 8:15-21

Melaku B (2012). Response of Common Bean (Phaseolus vulgaris L.) Cultivars with Different Growth Habits to Plant Density at Haramaya, Eastern Ethiopia. MSc. thesis at Haramaya University.68p.

Mohamad.O, Suhaimi.O and Abdullah M. Z. (1994). The relationships between harvest index, grain yield and biomass in rice. MARDI Res. J., 22: 29-34.

Monpara BA and Gaikwad SR (2014). Variation of Harvest Index in Several Crosses of Chick pea(Cicer arientinum L.). International Journal of Life Sciences, 3: 49-53.

Nwankwo I.I.M., Akinbo O.K., Ikoro A.I., Orji N.A.C and Njoku T.C (2018). Evaluation of selected sweet potato landraces for high harvest index and high root yield indices for parental selection. Int. J. Agric. Pol. Res., 6: 90-97.

Pilbeam C.J. (1996). Variation in harvest index of maize (Zea mays) and common bean (Phaseolus vulgaris) grown in a marginal rainfall area of Kenya. Journal of Agricultural Science, Cambridge, 126: 1-6.

Pinto Júnior R.A., Patto M.A., Martins E.S. and Abreu Â.D.F.B (2018). Inheritance of harvest index in common bean. Crop Breeding and Applied Biotechnology, 18: 252-258.

Reddy Y.N., Shaanker R.U., Prasad T.G. and Kumar M.U (2003). Physiological approaches to improving harvest index and productivity in sunflower. Helia, 26: 81-90.

Reynolds M. and Langridge P (2016). Physiological breeding. Curr. Opin. Plant Biol. 31: 162-171.

Rosielle Alber (1975). Inheritance, heritability, and correlation studies on harvest index and related traits in oats (avena sativa L.). Dissertation Submitted to the Graduate Faculty in Partial Fulfillment of the Requirements for the Degree of Doctor of Philosophy. 91p.

Sadras V.O and Richards R.A (2014). Improvement of crop yield in dry environments: benchmarks, levels of organization and the role of nitrogen. Journal of experimental botany, 65:1981-1995.

Sharifi R.S., Sedghi M. and Gholipouri A (2009). Effect of population density on yield and yield attributes of maize hybrids. Research Journal of Biological Sciences, 4: 375-379.

Sharma-Natu P and Ghildiyal, M.C (2005). Potential targets for improving photosynthesis and crop yield. Current Science 88: 1918-1928.

Siebert S., Ewert F., Rezaei E.E., Kage H. and Grab R., (2014). Impact of heat stress on crop yield on the importance of considering canopy temperature. Environmental Research Letters, 9: 1-8.

Sinclair TR (1998). Historical changes in harvest index and crop nitrogen accumulation. Crop Sci 38: 638-643.

Tadesse D, Alem T, Wossen T and Sintayehu A (2014). Evaluation of improved varieties of haricot bean in West Belessa, Northwest Ethiopia. International Journal of Science and Research, 3: 2756-2759.

Ugarte C., Calderini, D.F and Slafer G.A., 2007. Grain weight and grain number responsiveness to pre-anthesis temperature in wheat, barley and triticale. Field Crops Research, 100: 240-248.

Unkovich M., Baldock J. and Forbes M (2010). Variability in harvest index of grain crops and potential significance for carbon accounting: examples from Australian agriculture. In Advances in agronomy. 105 : 173-219. Academic Press.

Ur-Rehman A, Saleem M and Naveed A (2005). Genetic analysis of harvest index in mung bean. Pak. J. Agric. Sci, 42:66-70.

White E.M and Wilson F.E.A (2006). Responses of grain yield, biomass and harvest index and their rates of genetic progress to nitrogen availability in ten winter wheat varieties. Irish Journal of Agricultural and Food Research, 45: 85-101

Wilson D. R (1987). New approaches to understanding the growth and yield of pea crops. Agronomy Society of New Zealand, 6:23-28.

Wnuk A., Gorny A.G., Bocianowski J., Kozak, M (2014). Visualizing harvest Index in crops. Communications in Biometry and Crop Science, 8: 48-59.

Yang J. and Zhang J. (2010). Review Paper: Crop management techniques to enhance harvest index in Rice. Journal of Experimental Botany, 61: 3177-3189. 